\title{
Simple monitoring of fine chemical runaway reactions in multipurpose plants:
}

\author{
the nitration of 2,4-dichloro benzotrifluoride.
}

\author{
Francesco Maestri ${ }^{\mathrm{a}}$, Stefano Curti ${ }^{\mathrm{b}}$, Renato $\operatorname{Rota}^{\mathrm{a}^{*}}$ \\ a Politecnico di Milano, Dip. di Chimica, Materiali e Ingegneria Chimica “G. Natta”, \\ Piazza Leonardo da Vinci, 32 - 20133 Milano - Italy \\ ${ }^{\mathrm{b}}$ Currently at Seitru SRL \\ Blv. Mihai Viteazul Nr. 100/i bis, locatia 5 Zalau, Salaj, Romania \\ *renato.rota@polimi.it, fax: +390223993180
}

\begin{abstract}
$\underline{\text { Abstract }}$
In the fine chemical industry new production processes are often implemented in multipurpose existing plants with minimum adaptation investments. When the new process involves a potential runaway reaction, a full thermodynamic and kinetic characterization of the system should be performed to evaluate whether the reaction can be safely scaled-up in the selected plant. However, a detailed kinetic characterization is often unsuited because of the huge development rate of new products. In this work a potential runaway reaction of the agrochemical industry, that is, the nitration of 2,4-dichloro benzotrifluoride through mixed acids, is investigated with the aim of implementing it with a minimum experimental effort in an existing plant already dedicated to a similar reaction, that is, the nitration of 4-chloro benzotrifluoride. It has been shown that, even performing very similar reactions, the $\Psi$ number criterion cannot be implemented in a univocal way to monitor the multipurpose SBR operation. Such a goal can instead be reached through the general procedure based on the $\Psi, \mathrm{X}$ and $\mathrm{MTSR}_{\mathrm{ad}}$ set of process indicators, which was previously applied to the monitoring of polymerization processes.
\end{abstract}

Keywords:

Multipurpose Plant; Semibatch Reactor (SBR); Safety; Key Process Indicators; Early Warning; Combined Monitoring. 


\section{Introduction}

When dealing with non-continuous processes of the fine chemical industry, frequent production changes must be managed in multipurpose plants, within relatively short time periods. The same is true for industrial implementations of new products based on the final market requirements ${ }^{1}$ Therefore, the flexibility in such changes is nowadays a crucial challenge for the profitability of the involved business.

However, in several cases the production processes to be implemented may have safety constraints, e.g., due to relatively fast and exothermic reactions or to thermal stability problems of the reaction mass. Even when scaling-up such reaction processes the time required for a standard safety assessment $^{2}$ could conflict with the time available for implementing the process. Consequently, it is important developing safety criteria allowing for a quick investigation of the reaction safety conditions at the laboratory or pilot scale with a minimum experimental effort.

In the process safety literature of the last decades several short-cut criteria have been developed to identify safe and productive operating conditions of exothermic semi-batch reactors (SBRs) without solving the mathematical model of the system, therefore saving a considerable amount of time ${ }^{3-11}$. However, such criteria require to characterize the chemical kinetics of the reactions involved, which is often not compatible with the time constraints to be faced when a rapid process turnover must be managed in an existing plant. For this reason, a family of criteria (referred to as energy criteria) which allow for a kinetic-free selection of the safe process conditions and for their monitoring on the basis of an early warning approach has been recently presented ${ }^{12-14}$.

In this work a case study involving a potential runaway nitration reaction of the agrochemical industry is investigated, that is, the nitration of 2,4-dichloro benzotrifluoride (in the following referred to as 2,4-diCl BTF) to produce 2,4-dichloro 5-nitro benzotrifluoride (in the following referred to as 2,4-diCl 5-NO $\left.\mathbf{N O}_{\mathbf{2}} \mathbf{B T F}\right)^{15}$, an intermediate product for the final synthesis of substituted trifluoromethyl-diphenyl ethers, widely used as herbicides ${ }^{16}$. 
Based on a full thermodynamic and kinetic characterization of the reaction system, it has been taken into exam the implementation of the new process in an existing multipurpose plant, where the similar nitration of 4 -chloro benzotrifluoride ${ }^{17,18}$ (in the following referred to as 4-Cl BTF) is performed on a campaign logic. In particular, the safe and productive operating conditions of the new process have been identified through both the boundary / temperature diagrams criterion ${ }^{9}$, and the energy criteria ${ }^{12-14}$, showing that through the latter method the same results can be obtained with a much lower experimental effort; this allows for a faster industrial implementation of the new process and for an effective monitoring of the safe SBR regime during each reaction batch, through the continuous measurement of some Key Process Indicators.

Moreover, it has been found that, even performing in the same SBR similar reactions such as the mixed acid nitration of 4-Cl BTF and 2,4-diCl BTF, the $\Psi$ number criterion cannot be univocally implemented in order to monitor the safe reactor operation without false alarms. This is due to the different sensitivity of the reaction rate to the charged reactant concentration that can induce a $\Psi$ number decay in the last part of the dosing period. To solve this problem a more complete set of Key Process Indicators needs to be implemented in the SBR: such a set is the same previously proposed specifically for monitoring polymerization processes ${ }^{13}$, which experience thickening phenomena of the reaction mass and a consequent decay of the reactor heat-transfer efficiency.

\section{Reaction system characterization}

Nitro derivatives are well known to have a limited thermal stability with temperature ${ }^{19,20}$. Moreover the final nitration mixture with mixed acids is known to decompose through the transient generation of highly unstable sulfonated intermediates of the nitro compound, produced through its reaction with the sulfuric acid excess ${ }^{21}$. This is confirmed by the thermal behavior of the system characterized through differential scanning calorimetry (DSC) experiments performed in a Mettler Toledo DSC 820 equipment ${ }^{15}$ as briefly summarized in the following. 
We can see from Figure 1 that no thermal effects have been detected for 2,4-diCl BTF, while for 2,4-diCl 5- $\mathrm{NO}_{2}$ BTF the endothermic thermal effect due to the product melting at $53^{\circ} \mathrm{C}{ }^{22}$ is well detectable, followed by a thermal decomposition occurring at $380^{\circ} \mathrm{C}$ with a reaction enthalpy of 275kJ/mol. Note that for 2,4-diCl 5-NO2 $\mathbf{B T F}$ the maximum investigated temperature is higher than that for 2,4-CI BTF, in spite the latter was already higher than the temperatures of interest for the process. This allowed to detect the decomposition phenomenon of the product, as expected dealing with a nitro-derivative.

Figure 2 shows, for different heating rate values, the thermal characterization of the final reaction mixture. We can see that, after an endothermic effect corresponding to the final product melting in the two-phase system, two further exothermic effects have been detected: the first one can be related to the second nitration of a slight fraction of the final product by the nitric acid excess, while the second one is much more severe and related to the reaction mass decomposition. As usual, decreasing the heating rate lowers the temperatures at which the two events are detected. In any case, we can see that the presence of sulfuric acid significantly lowers the thermal stability of the final product (that is, 2,4-diCl 5-NO $\mathbf{N O}_{2} \mathbf{B T F}$ ), which decomposition occurs nearly $200^{\circ} \mathrm{C}$ below that of the pure species, and hence in a temperature range much closer to the maximum temperatures potentially attainable during the reaction process. Such a result is consistent with the well-known destabilizing effect on many nitro derivatives by even traces of sulfuric acid ${ }^{21}$ : for this reason, in nitration plants the final reaction mixture is typically washed with slightly alkaline solutions before its final storage ${ }^{23}$.

The final mixture decomposition temperature has been then better estimated through adiabatic calorimetry tests performed in an ARC equipment by Columbia Scientific Instruments ${ }^{15,19}$ with a thermal inertia factor equal to 4.5 (to be used for the correction of the temperature increase data) and adopting a standard heat-wait-search (HWS) sequence, with a temperature increase during the heating phase ranging from 5 to $10^{\circ} \mathrm{C}$ and a duration of the subsequent waiting period of $15-30$ minutes. During the waiting period, self-heating rates larger than $0.02^{\circ} \mathrm{C} /$ minute can be detected 
according to the instrument accuracy. If the self-heating rate of the sample during the waiting period is larger than $0.02^{\circ} \mathrm{C} /$ minute, the equipment shifts to the adiabatic mode following the development of the exothermic effect up to its completion. With this technique, the decomposition temperature of the final reaction mixture resulted to be close to $140^{\circ} \mathrm{C}^{15}$, as reported in the literature also for the 4Cl BTF nitration system ${ }^{17,18}$.

As expected, a lower decomposition temperature of the final reaction mixture has been detected in the ARC tests with respect to the DSC runs because of the higher accuracy of the adiabatic calorimetry techniques $^{19}$. Therefore, for the process evaluations a reaction mass decomposition temperature equal to $140^{\circ} \mathrm{C}$ can be assumed. Moreover, since the thermal stability results obtained on an aged reaction mass do not significantly differ from those on the non-aged one ${ }^{15}$, it can be also concluded that the decomposition mechanism is not autocatalytic.

Apart from the preliminary investigation of the thermal stability of the involved species and mixtures, the main synthesis reaction (that is, the nitration of 2,4-diCl BTF in mixed acids through the nitronium ion mechanism) must be characterized for scaling-up the process to the industrial plant.

According to a chemical recipe developed at the laboratory scale (see Table 1), 2,4-diCI BTF can be added in a suitable dosing time to a stirred mixture of sulfuric and nitric acid in an indirectly cooled SBR at an average temperature of $60^{\circ} \mathrm{C}$. 2,4-diCI BTF (A), poorly soluble in the continuous acidic phase, diffuses into it and reacts with nitric acid (B) through the nitronium ion mechanism to yield 2,4-diCl 5-NO $\mathbf{N O}_{2}$ BTF (C) and water (D), according to the reaction:

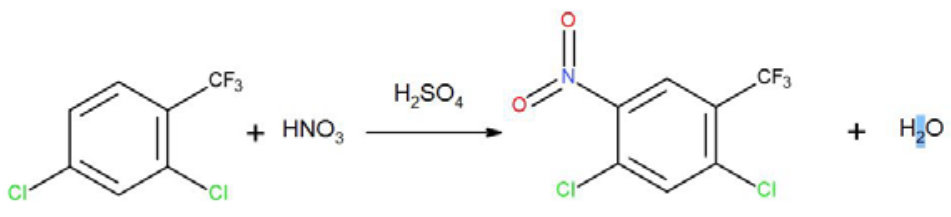

$$
2,4-\mathrm{diCl} \mathrm{BTF}+\mathrm{HNO}_{3} \stackrel{\mathrm{H}_{2} \mathrm{SO}_{4}}{\longrightarrow} 2,4-\mathrm{diCl} 5-\mathrm{NO}_{2} \mathrm{BTF}+\mathrm{H}_{2} \mathrm{O}
$$

The reaction enthalpy, estimated through the Benson contribution group method for condensed 
phases $^{24}$ and accounting also for the heat of mixing between the acidic mean and the generated water, is equal to $-152 \mathrm{~kJ} / \mathrm{mol}$. Such a value agrees with the expected order of magnitude for several aromatic nitrations ${ }^{17-19}$.

According to this reaction enthalpy value and to the adopted chemical recipe, an adiabatic temperature rise equal to:

$\Delta \mathrm{T}_{\mathrm{ad}}=\frac{\left(-\Delta \widetilde{\mathrm{H}}_{\mathrm{r}}\right) \times \mathrm{n}_{\mathrm{A} 1}}{\left(\mathrm{~m} \widehat{\mathrm{C}}_{\mathrm{P}}\right)_{\mathrm{c}}+\left(\mathrm{m} \widehat{\mathrm{C}}_{\mathrm{P}}\right)_{\mathrm{d}}} \approx 108^{\circ} \mathrm{C}$

can be calculated, where $\mathrm{n}_{\mathrm{A} 1}$ is the whole molar amount of the dosed 2,4-diCI BTF (with respect to which a 9\% nitric acid excess is used) and the heat capacity of the continuous acidic phase and of the dispersed organic phase are equal to $1.477 \mathrm{~kJ} /\left(\mathrm{kg}^{\circ} \mathrm{C}\right)$ and $1.177 \mathrm{~kJ} /\left(\mathrm{kg}^{\circ} \mathrm{C}\right)$, respectively ${ }^{22}$. Considering that the average temperature at which the reaction is performed is equal to about $60^{\circ} \mathrm{C}$, a maximum adiabatic temperature attainable by the synthesis reaction when all the coreactant is consumed:

$\operatorname{MTSR}_{\mathrm{ad}, 0}=\mathrm{T}_{\mathrm{r}}+\Delta \mathrm{T}_{\mathrm{ad}} \approx 168^{\circ} \mathrm{C}$

can be expected, which is well above the detected decomposition threshold of the system (that is, about $140^{\circ} \mathrm{C}$ ). Therefore, the process belongs to the most critical category of potential runaway reactions, according to Stoessel's classification ${ }^{25}$. The same result was found for the 4-Cl BTF nitration $^{18}$.

Since a heterogeneous liquid-liquid reaction system is involved, two sets of isothermal experiments are required (say, in a Mettler Toledo 1.2L RC1 calorimeter) to characterize properly the reaction microkinetics: the first one at different reaction temperatures and the second one at different stirring speeds $^{26,27}$.

In the reference experiment a reaction temperature of $60^{\circ} \mathrm{C}$, a stirring speed of 300rpm (that is, above the limit at which a homogeneous and stable emulsion between the two liquid phases was obtained) and a uniform dosing of 2,4-diCl BTF over a three hours dosing time has been adopted ${ }^{15}$. After dosing all the 2,4-diCl BTF, the reaction mass was kept under stirring at the selected 
temperature for up to three more hours, to reach an almost complete conversion. The dosing time at the RC1 scale was taken from the industrially adopted operating conditions for the similar 4-Cl BTF nitration $^{18}$. Such a choice is conservative, because of the higher heat transfer surface per unit volume characterizing a laboratory reactor with respect to a full scale one ${ }^{9}$.

Four more isothermal RC1 experiments have been performed, one of which at a stirring speed of $300 \mathrm{rpm}$ and at reaction temperatures of $55^{\circ} \mathrm{C}$, and three at $60^{\circ} \mathrm{C}$ and at decreasing stirring speeds, equal to 150,130 and $100 \mathrm{rpm}$, respectively ${ }^{15}$. In all the reaction runs, the heat removal rate for keeping the reaction temperature at the selected constant value was measured during the coreactant dosing as well as during the completion period after it, as shown in Figure $3^{15}$.

After the supply period, a residual amount of heat must be removed from the system arising from the conversion of the coreactant accumulated in the SBR at the end of the dosing period. Therefore, the percentage ratio of such a residual amount of heat to the whole energy contribution of the reaction, $\Gamma$ :

$\Gamma=\frac{\int_{\mathrm{t}_{\text {dos }}}^{\infty} \dot{\mathrm{Q}}_{\text {cool }} \mathrm{dt}}{\int_{0}^{\infty} \dot{\mathrm{Q}}_{\text {cool }} \mathrm{dt}} \times 100=\frac{\int_{0}^{\infty} \dot{\mathrm{Q}}_{\text {cool }} \mathrm{dt}-\int_{0}^{\mathrm{t}} \mathrm{dos} \dot{\mathrm{Q}}_{\text {cool }} \mathrm{dt}}{\int_{0}^{\infty} \dot{\mathrm{Q}}_{\text {cool }} \mathrm{dt}} \times 100=\left[1-\frac{\int_{0}^{\mathrm{t} d o s} \dot{\mathrm{Q}}_{\text {cool }} \mathrm{dt}}{\mathrm{n}_{\mathrm{A} 1}\left(-\Delta \widetilde{\mathrm{H}}_{\mathrm{r}}\right)}\right] \times 100$

is a measure of the coreactant accumulation (in percentage) at the end of the supply period; in this relation $\mathrm{n}_{\mathrm{A} 1}\left(-\Delta \widetilde{\mathrm{H}}_{\mathrm{r}}\right) \cong 237 \mathrm{~kJ}$ is the energy released by the conversion of the whole amount of the dosed 2,4-diCI BTF (which is, as previously mentioned, the limiting reactant).

From the data reported in Figure 3, the results of the five RC1 experiments can be recast in terms of coreactant accumulation values, as plotted in Figure 4 for the isothermal runs at $60^{\circ} \mathrm{C}$ (that is, at the selected reaction temperature). We can see that at a stirring speed of 300rpm the coreactant accumulation at the end of the supply period is well below $10 \%$, that is, the reaction goes almost to completion within the dosing period.

Under such conditions the reaction process is under control since the reaction temperature is far below the decomposition limit and the SBR shutdown occurs almost simultaneously with the 
coreactant feed interruption, as a consequence of the negligible accumulation of the unreacted coreactant in the system all along the dosing period.

Performing the tests at decreasing stirring speeds (see Figure 3B) the characteristic time of the involved mass transfer phenomena increases, so that the mass transfer resistances play a not negligible role and a consequent accumulation in the fast reaction regime is observed ${ }^{5,27}$. At the stirring speed of 130rpm, such an accumulation leads to a delayed and higher heat removal rate peak as the reaction triggers. Consequently, the heat removal rate does not drop to negligible values neither at the end of the supply period nor at any intermediate feed interruption which, for this reason, does not yield to a sudden SBR shutdown. In the experiment performed at 100rpm the process ignition is strongly compromised, due to the huge mass transfer resistances within a liquidliquid emulsion next to the phase separation ${ }^{27}$. As can be noticed from the time profile of Figure 3B, in this case the conversion goes on at a relatively low and nearly constant rate well beyond the end of the dosing and completion periods, which is the typical behavior of heterogeneous reaction systems operated under mass transfer limitations ${ }^{27}$.

As can be recognized from the data summarized in Figure 4, it can be concluded that the influence of the mass transfer resistances on the RC1 reactor operation steeply decreases above 150rpm. This enables for using the calorimetric data of the tests performed at 300rpm for estimating the microkinetic parameters of the reaction.

Under isothermal conditions and with a dosing stream temperature equal to the reaction temperature, the energy balance of the RC1 reactor in the slow reaction regime, neglecting any heat loss contribution as well as the mechanical work of the stirrer, yields ${ }^{18}$ :

$\dot{\mathrm{Q}}_{\text {cool }}=\dot{\mathrm{Q}}_{\mathrm{r}}=\mathrm{r}^{\mathrm{eff}} \mathrm{V}_{\mathrm{r}}\left(-\Delta \widetilde{\mathrm{H}}_{\mathrm{r}}\right)=\mathrm{k}_{0} \cdot \exp \left(\frac{-\mathrm{E}_{\mathrm{act}}}{\mathrm{RT}}\right) \cdot \mathrm{m}_{\mathrm{A}}^{\mathrm{n}} \cdot \mathrm{C}_{\mathrm{A}_{\mathrm{d}}}^{\mathrm{n}} \cdot \mathrm{C}_{\mathrm{B}_{\mathrm{c}}}^{\mathrm{m}} \cdot \mathrm{V}_{\mathrm{r}} \cdot\left(-\Delta \widetilde{\mathrm{H}}_{\mathrm{r}}\right)$

where, for $0 \leq \mathrm{t}<\mathrm{t}_{\text {dos }}$ :

$\mathrm{C}_{\mathrm{A}_{\mathrm{d}}}=\mathrm{C}_{\mathrm{A}, \mathrm{dos}}\left(1-\frac{\mathrm{t}_{\mathrm{dos}}}{\mathrm{t}} \zeta\right)$

$\mathrm{C}_{\mathrm{B}_{\mathrm{c}}}=\mathrm{C}_{\mathrm{BO}_{\mathrm{c}}}(1-\zeta)$ 
and, for $\mathrm{t} \geq \mathrm{t}_{\text {dos: }}$ :

$\mathrm{C}_{\mathrm{A}_{\mathrm{d}}}=\mathrm{C}_{\mathrm{A}, \mathrm{dos}}(1-\zeta)$

The time behavior of the nitric acid (B) concentration can instead be derived solving the mass balance equation:

$\frac{\mathrm{d} \zeta}{\mathrm{dt}}=\frac{\mathrm{k}_{0} \cdot \exp \left(\frac{-\mathrm{E}_{\mathrm{act}}}{\mathrm{RT}}\right)}{\mathrm{C}_{\mathrm{B}_{\mathrm{c}}}} \cdot\left(\mathrm{m}_{\mathrm{A}} \cdot \mathrm{C}_{\mathrm{A}_{\mathrm{d}}}\right)^{\mathrm{n}} \cdot \mathrm{C}_{\mathrm{B}_{\mathrm{c}}}^{\mathrm{m}}$

being $\zeta=0$ at $\mathrm{t}=0$.

The best fit between the experimental and calculated heat removal rate data (accounting for the conversion of the dosed reactant as well as of its accumulated amount) in the reaction runs performed at 300rpm has been carried out, leading to the following kinetic expression:

$\mathrm{r}_{2,4-\mathrm{diCl} \mathrm{BTF}}=2.85 \cdot 10^{12} \cdot \exp \left(-\frac{87700}{8.314 \cdot \mathrm{T}}\right) \cdot \mathrm{m}_{\mathrm{A}} \cdot \mathrm{C}_{\mathrm{A}_{\mathrm{d}}} \cdot \mathrm{C}_{\mathrm{B}_{\mathrm{c}}}^{0.2}$

Equation (10) can be compared with that describing the nitration rate of 4-Cl BTF in the same conditions, as reported in the literature ${ }^{17,18}$ :

$\mathrm{r}_{4-\mathrm{Cl} \mathrm{BTF}}=3.228 \cdot 10^{12} \cdot \exp \left(-\frac{87260}{8.314 \cdot \mathrm{T}}\right) \cdot \mathrm{m}_{\mathrm{A}} \cdot \mathrm{C}_{\mathrm{A}_{\mathrm{d}}} \cdot \mathrm{C}_{\mathrm{B}_{\mathrm{C}}}$

Since a chemical reaction is the result of collisions between the reactant molecules of sufficiently high energy and effective orientation, a reaction rate equation can be expressed as the product of a probability factor, of an energy factor and of a concentration factor ${ }^{28}$. Comparing Equations (10) and (11) it can be noticed that:

- the probability factors of the two reactions, expressed by the pre-exponential factors, slightly differ from each other, which is expected being the two reactions of the same class;

- the activation energies of the two reactions are close to each other, which is also expected. In fact, the substitution of the original aromatic ring with a second halogen atom yields an only slight deactivating effect for the further introduction in the ring of another substituent $^{29,30}$. Such a behavior is qualitatively also proved by the ortho-para orientation of the electrophilic attack with respect to the halogen, which is instead typical of electron 
donor activating substituents. This suggests that the deactivating effect of a halogen substituent is relatively low, so that its behavior in terms of orientation is partially superimposed with that of activating substituents;

- $\quad$ at a given nitric acid concentration the concentration factor is lower for the nitration of 2,4diCl BTF, as expressed by the lower reaction order with respect to nitric acid. Also, this behavior is expected, considering that the molecule of 4-Cl BTF has two equiprobable ortho positions with respect to the halogen for the nitro group substitution. 2,4-diCl BTF, instead, has one favored position for this attack, that is, position 5 with respect to the trifluoromethyl group. Position 3, in fact, is not equally available because of steric hindrance reasons. It follows that at a given nitric acid concentration the frequency of effective collisions is higher for 4-Cl BTF.

\section{Safe reaction scale-up and monitoring}

In the previous section the reaction system for the 2,4-diCI BTF nitration through mixed acids has been analyzed in terms of thermal stability of the involved products and mixtures, as well as in terms of the relevant thermodynamic and kinetic parameters of the main reaction.

From these information, the operating conditions for safely performing and monitoring the reaction at the full plant scale can now be identified.

In particular, provided that the reaction temperature is defined by the chemical recipe, a suitable 2,4-diCI BTF dosing time must be selected, allowing for both a nearly instantaneous consumption of the fed coreactant and a relatively narrow variation of the reaction temperature around its average value $^{12,13}$. This can be done through two methods, that is the combined boundary and temperature diagrams criterion ${ }^{9}$ and the energy criterion ${ }^{12-14}$.

According to the chemical recipe, operating the SBR under isoperibolic conditions and under intensive stirring (so as to minimize the mass transfer limitations), a temperature range between 55 and $65^{\circ} \mathrm{C}$ can be reasonably accepted during the coreactant dosing. With such an assumption a dimensionless temperature rise: 
$\psi=\left(\mathrm{T}_{\max } / \mathrm{T}_{0}\right)_{\max } \cong 1.03$

can be calculated, to which an exothermicity parameter:

$\mathrm{E}_{\mathrm{x}}=\frac{\gamma}{\breve{\mathrm{T}}_{0}^{2}} \frac{\Delta \breve{\mathrm{T}}_{\mathrm{ad}, 0}}{\varepsilon\left(\mathrm{Wt}+\mathrm{R}_{\mathrm{H}}\right)} \cong 1$

corresponds under Quick Onset-Fair Conversion-Smooth Temperature Profile (QFS) conditions, as can be read from the general temperature rise curve reported in the literature ${ }^{9,18}$.

On the basis of the industrial SBR data summarized in Tables 2, a Westerterp number ${ }^{31}$ :

$\mathrm{Wt}=\frac{\left.(\mathrm{UA})_{\mathrm{H}}\right)_{\mathrm{dos}}}{\varepsilon\left(\tilde{\rho} \widetilde{\mathrm{C}}_{\mathrm{P}} \mathrm{V}\right)_{\mathrm{c}}} \cong 40$

can be calculated, to which an estimated 2,4-diCI BTF dosing time equal to 4 hours corresponds.

The Westerterp number calculated above agrees with its typical values for well stirred reaction vessels equipped with jacket and coil, initially loaded with an aqueous phase ${ }^{32}$.

With the estimated dosing time, a reactivity number:

$\mathrm{R}_{\mathrm{y}}=\frac{v_{\mathrm{A}} \mathrm{DaRE} \cdot \mathrm{f} \cdot \mathrm{\kappa}\left(\breve{\mathrm{T}}_{0}\right)}{\varepsilon\left(\mathrm{Wt}+\mathrm{R}_{\mathrm{H}}\right)} \cong 0.81$

can be calculated at the full plant scale, to be finally compared with its QFS value for slow liquidliquid reactions occurring in the continuous phase $\mathrm{e}^{6,7}$.

For this purpose, even if the reaction is described by a $(1,0.2)$ order kinetics, the $R_{y, Q F S}$ value for $(1,1)$ reactions can be taken as a threshold lower limit, because the influence of the reaction order of the initially loaded reactant (in this case, nitric acid) on the shape and position of the boundary diagrams in the $\mathrm{E}_{\mathrm{x}}-\mathrm{R}_{\mathrm{y}}$ space can be normally neglected as a first approximation ${ }^{6,7}$.

Since in this case $\mathrm{R}_{\mathrm{y}, \mathrm{QFS}} \approx 0.013^{32}<<\mathrm{R}_{\mathrm{y}}=0.81$, it can be also concluded that the selected operating conditions at the industrial scale are QFS type, as assumed at the beginning on the basis of the initial system reactivity.

The criterion adopted here above allowed for a relatively straightforward estimation of the 2,4-diCl BTF dosing time, without solving the mathematical model of the SBR.

However the procedure involved the kinetic parameters of the main reaction, since it is based on a 
direct comparison between the coreactant dosing time and the reaction characteristic time ${ }^{12}$.

As shown in the previous sections, the estimation of the kinetic parameters requires an experimental effort that can be hardly carried out for the full set of products to be dealt with in a multipurpose plant of the fine chemical industry, given the strict time constraints to be faced when bringing to the industrial plant new reaction processes.

The problem can be significantly simplified in terms of experimental effort using the energy criterion $^{12-14}$ : such a criterion is based on a kinetic-free direct measurement of the approach of the SBR operating regime to given target conditions, under which the conversion rate does not depend on the reaction kinetics because of an intrinsically much slower dosing rate of the coreactant. For this reason the energy criterion allows for solving the problem bypassing the kinetic information and the related experimental effort.

The method is based on a targeted number of smaller scale isoperibolic experiments performed in a well stirred laboratory or pilot scale reactor, equipped for measuring the process variables used for the ongoing calculation of the $\Psi, \mathrm{X}$ and MTSR $_{\text {ad }}$ parameters, which are defined as $^{12-14}$ :

$\Psi=\frac{\mathrm{F}_{\text {dos }} \widetilde{\mathrm{C}}_{\mathrm{P}, \mathrm{dos}}\left(\mathrm{T}-\mathrm{T}_{\text {dos }}\right)+\dot{\mathrm{m}}_{\text {cool }} \widehat{\mathrm{C}}_{\mathrm{P}, \text { cool }}\left(\mathrm{T}_{\text {cool, OUT }}-\mathrm{T}_{\text {cool,IN }}\right)}{\frac{\mathrm{F}_{\mathrm{A}, \mathrm{dos}}}{{ }_{\mathrm{A}} \mathrm{A}}\left(-\Delta \widetilde{\mathrm{H}}_{\mathrm{r}}\right)} \times 100$

$\mathrm{X}=\frac{\left(\mathrm{m} \widehat{\mathrm{C}}_{\mathrm{P}}\right)_{0}\left(\mathrm{~T}-\mathrm{T}_{0}\right)+\left(\mathrm{m} \widehat{\mathrm{C}}_{\mathrm{P}}\right)_{\text {fed }}\left(\mathrm{T}-\mathrm{T}_{\mathrm{dos}}\right)+\int_{0}^{\mathrm{t}}\left(\dot{\mathrm{m}} \widehat{\mathrm{C}}_{\mathrm{P}} \Delta \mathrm{T}\right)_{\text {cool }} \mathrm{dt}}{\left(-\Delta \widehat{\mathrm{H}}_{\mathrm{r}}\right) \mathrm{m}_{\mathrm{fed}}{ }_{\mathrm{A}} \mathrm{A} / \mathrm{v}_{\mathrm{A}}} \times 100$

$\operatorname{MTSR}_{\mathrm{ad}}=\mathrm{T}+(1-\vartheta \mathrm{X} / 100) \Delta \mathrm{T}_{\mathrm{ad}}$

As discussed in the literature ${ }^{12-14}$ :

- $\quad \Psi$ is a measure of the degree of approximation of the system to an operating regime under which the time scales for the consumption of the dosed coreactant by the chemical reaction as well as for the removal of the related heat of reaction by the cooling system are negligible. Therefore, a value of $\Psi$ equal to 100 characterizes a theoretical operating regime of the SBR under which the dosed coreactant is instantaneously converted and the related heat of reaction is instantaneously removed from the system. $\Psi$ values lower than 100 
characterize operating regimes where such ideal conditions are not met; however, the lowest acceptable value is arbitrarily defined (say, 80) for taking into account for the unavoidable displacement of the real system from the aforementioned ideal conditions.

- $\quad \mathrm{X}$ is a measure of the integral conversion degree of the fed coreactant by the chemical reaction. Therefore, a $\mathrm{X}$ value equal to 100 at a given time corresponds to a quantitative conversion of the coreactant fed up to that time;

- MTSR $_{a d}$ is the temperature potentially reached by the system if, starting from the time considered, all the coreactant to be still dosed as well as its accumulated amount were converted into the final reaction product under adiabatic conditions. For instance, under fully non ignition reaction conditions (to which a constant $X=0$ value corresponds) and at the beginning of the supply period (that is, at $\vartheta=0$ ), MTSR $_{a d}$ equals MTSR $_{a d, 0}$, calculated through Equation (3).

It must be stressed that the aforementioned experiments can be performed even in a reactor different from an RC1 calorimeter, which use could be critical when exploring for the first time potentially dangerous reactions, such as the nitration in question ${ }^{23}$.

In order to minimize the number of smaller scale experiments required for identifying the optimal set of operating conditions, it is useful to estimate an upper limit of the dosing time to be expected at such a scale: in this way the trial and error runs to be performed at decreasing corectant feed rates can be overcome, with a significant saving of time.

The preliminary estimation of a conservative value of the dosing time can be performed through the following equation ${ }^{18}$ :

$t_{d o s} \leq m_{d o s} \frac{\frac{\omega_{A} A}{v_{A}}\left(-\Delta \widehat{H}_{r}\right)+\widehat{C}_{P, d o s}\left(T_{d o s}-\bar{T}\right)}{\left(U A_{H}\right)_{a v g}\left(\bar{T}-T_{\text {cool }}\right)}$

Such an expression is based on a $\Psi$ number profile theoretically equal to 100 for a fully triggered reaction, and hence provides a conservative estimation of the dosing time with respect to SBR operating conditions under which a $\Psi$ number value between 80 and 100 can be usually accepted in

\section{DOI: 10.1021/acs.iecr.7b04696}


the first part of the supply period.

On the basis of the operating parameters summarized in Tables 2 for the smaller scale experiments performed in the RC1 equipment, an upper limit of the coreactant dosing time at the RC1 scale equal to 2 hours can be calculated.

Three RC1 runs have been simulated with dosing times equal to 0.5, 1 and 1.5 hours respectively, in which the $\Psi$ number value at the $20 \%$ of the dosing period has been computed and compared with the lower threshold of $80^{12}$.

It should be noted that even if a full 2,4-diCl BTF accumulation occurred in such a first fraction of the supply period (for the sake of example because of an insufficient stirring speed, subsequently increased) the sudden evolution of the reaction heat due to its conversion would lead under adiabatic conditions to a temperature rise of:

$\Delta \mathrm{T}_{\mathrm{ad}, 20 \%}=\frac{\left(-\Delta \widetilde{\mathrm{H}}_{\mathrm{r}}\right) \times \mathrm{n}_{\mathrm{A} 1 \times 0.2}}{\left(\mathrm{~m} \widehat{\mathrm{C}}_{\mathrm{P}}\right)_{\mathrm{c}}+0.2 \times\left(\mathrm{m} \widehat{\mathrm{C}}_{\mathrm{P}}\right)_{\mathrm{d}}} \approx 25^{\circ} \mathrm{C}$

and therefore to a final temperature (equal to $55+25=80^{\circ} \mathrm{C}$ ) well below the decomposition limit of the reaction mass (that is, $140^{\circ} \mathrm{C}$ ).

It should be noted that the identification of the safe and productive dosing time is better performed on the basis of the $\Psi$ number (among the other energy parameters), measured at a suitably early fraction of the supply period. In this way, in fact, the reaction system can be characterized at the lower scale with respect to both its quick onset and expected heat removal efficiency ${ }^{12}$ : this allows also for detecting too early thickening phenomena of the reaction mass (due e.g. to an excessive system concentration), which would occur when the energy release potential of the system could lead under low heat transfer conditions to excessive peak temperatures ${ }^{13}$.

According to the results plotted in Figure 5 for the three aforementioned conditions, an average 2,4diCl BTF dosing time of 1.25 hours can be safely selected at the RC1 scale, taking into account also for the unavoidable fluctuations to be expected in the measurement of $\Psi^{12}$. To such a dosing time an RC1 scale Westerterp number ${ }^{31}$ again equal to 40 corresponds. 
Once the 2,4-diCl BTF dosing time has been selected at the lower scale (that should be also experimentally validated before scaling-up the process), its scale-up to the industrial SBR can be safely performed keeping the Westerterp number constant and adjusting it on the basis of the lower heat transfer efficiency per unit volume of the full scale $\mathrm{SBR}^{9}$. In this way a 2,4-diCl BTF industrial dosing time equal to 4 hours can be calculated, which confirms the estimation provided by the combined boundary and temperature diagrams criterion. However, in this case the experimental effort for identifying the full scale operating conditions was much lower, since no kinetic information was needed, resulting in a fewer isoperibolic runs with respect to the several isothermal ones required to estimate reliable kinetic parameters.

As shown in Figure 6, with the selected dosing time a $\Psi$ number value equal to about 90 at the $20 \%$ of the 2,4-diCl BTF feed can be expected at the industrial scale, together with a temperature variation during the semibatch period in the range from 55 to $64^{\circ} \mathrm{C}$.

Once a safe and productive set of operating conditions has been selected, the proper SBR operation must be monitored during each production batch, in order to early detect any process anomaly which could trigger a dangerous scenario ${ }^{33-35}$. This is of particular importance when dealing with nitration reactions, because of the limited thermal stability of the reaction mass ${ }^{19,33}$.

In the case study taken into exam the two reactions to be performed in the same SBR (that is, the 4Cl BTF and the 2,4-diCl BTF nitration through mixed acids), even belonging to the same class, differ from each other in their kinetic behavior and in some physical properties. Such differences have a relevant impact on the SBR monitoring through $\Psi^{13}$.

When dealing with the 4-Cl BTF nitration ${ }^{17,18}$, the higher dependence of the reaction rate on the continuous phase nitric acid concentration (which is expressed by a reaction order of 1 for nitric acid vs. 0.2 for the 2,4-diCl BTF nitration) causes in the final part of the supply period a normal reactivity decay and a consequent increase of the dosed coreactant accumulation: this causes a normal decrease of $\Psi$ down to values lower than the assumed threshold (that is, 80 ) in the last $10 \%$

\section{DOI: 10.1021/acs.iecr.7b04696}


of the supply period, hence triggering an undue alarm even under QFS conditions.

Such a behavior is typical of any reaction system with a significant concentration dependence of the reaction rate, for which a reactivity drop in the final part of the supply period must be expected even under safe conditions as a consequence of the full consumption of the initially loaded reactant. The same occurs for systems which reactivity depends (for instance) on the strength of an acidic reaction phase which is progressively diluted with the water generated by the reaction.

Therefore, the industrial implementation of the $\Psi$ criterion for monitoring such reactions requires the exclusion of the $\Psi$ number check in this last part of the supply period, in order to avoid false alarms, which would negatively affect the process continuity even under normal operating conditions.

The 2,4-diCl BTF nitration system, instead, undergoes a much smaller reactivity drop in the final part of the supply period, due to the full consumption of nitric acid: therefore, in this case, even keeping the $\Psi$ number check up to the end of the supply period, the plant monitoring device would not raise false alarms.

This means that even when monitoring two fully similar reactions performed in a multipurpose SBR, the monitoring strategy based on $\Psi$ should be adapted by the plant operator to each process, hence losing the generality of the criterion.

However, the 2,4-diCI BTF nitration system has another potential drawback, arising from a reactor operating temperature close to the melting point of 2,4-diCl $5-\mathbf{N O}_{2} \mathbf{B T F}$ (that is, $53^{\circ} \mathrm{C}^{15,22}$ ). Therefore, even a slight fluctuation of the average coolant temperature could cause an unexpected decay of the reactor heat transfer efficiency in the last part of the supply period as a consequence of icing phenomena on the heat transfer surfaces.

Such a scenario has been simulated in Figure 7, where the reaction temperature, $\Psi, \mathrm{X}$ and $\mathrm{MTSR}_{\mathrm{ad}}$ time profiles are plotted for a 50\% sudden drop of the reactor heat transfer efficiency occurring in the last $10 \%$ of the dosing period. 
The corresponding $\Psi$ number sudden decay would trigger also in this case an undue feed interruption occurring under full ignition reaction conditions in the final part of the supply period, that is, when the energy release potential of the system in terms of conversion of the coreactant to be dosed (as well as of its accumulated amount) is unable to induce a dangerous temperature rise. On the contrary, such a feed interruption would affect the regular process conduction, with a corresponding loss of productivity.

Despite the aforementioned differences affecting even similar reaction systems performed in a multipurpose SBR, a univocal monitoring strategy could instead be guaranteed adopting the same general procedure developed in the literature for polymerization systems, that is, for systems undergoing potential changes in the heat transfer efficiency during the process. Such a procedure, based on a suitable monitoring sequence of the full set of key process indicators given by $\Psi, \mathrm{X}$ and MTSR $_{a d}$, allows for univocally triggering the emergency action only when facing a reaction inhibition or an early heat transfer efficiency drop which could lead to overcoming a maximum allowable temperature for the reaction system.

Therefore, even performing several reaction processes in the same SBR on a campaign basis, a univocal monitoring strategy can be adopted through $\Psi, \mathrm{X}$, and MTSR $\mathrm{ad}$.

As can be seen from the results plotted in Figures 8 to 10, dealing with the 4-Cl BTF nitration the final process continuity would be kept in this way, because of both an MTSR $_{a d}$ value lower than the MAT and a not relevant X number decrease arise.

Analogously, performing the 2,4-diCI BTF nitration, icing phenomena due to the final product solidification on the heat transfer surfaces would not affect the process continuity because of both an MTSR $_{a d}$ value lower than the MAT and an even increasing trend of $\mathrm{X}$ arise.

It must be finally pointed out that any monitoring procedure of the SBR cannot replace a properly sized pressure relief system (for instance, a bursting disk) to protect the reactor and interconnected equipment against the incidental decomposition of the reaction mass ${ }^{36}$. However, adopting a 
suitable SBR motoring is useful to minimize the frequency of occurrence of anomalous process scenarios and related plant shutdown.

\section{4. $\underline{\text { Conclusions }}$}

In multipurpose plants of the fine chemical industry, the same equipment is dedicated in its lifetime to several reaction processes, some of which can undergo safety problems due to potential runaway reactions. When scaling-up a new process of this type, it is crucial to minimize the time and costs for a reliable safety assessment aimed to identify suitable operating conditions on the existing SBR. Moreover, a simple and robust monitoring procedure of the SBR must be set up, allowing for safely performing all the reactions to be dealt with at the expected production rate.

In this work the scale-up of a potential runaway nitration process of the agrochemical industry has been discussed with the aim of implementing it in an SBR already dedicated to a reaction of the same class on a campaign basis.

After the identification of the safe and productive operating conditions of the new process through the energy criteria with a minimum experimental effort, it has been shown that the general procedure previously developed for monitoring reaction systems potentially undergoing significant changes of their physical properties is also useful for unifying the monitoring strategy of a multipurpose SBR. 


\section{Nomenclature}

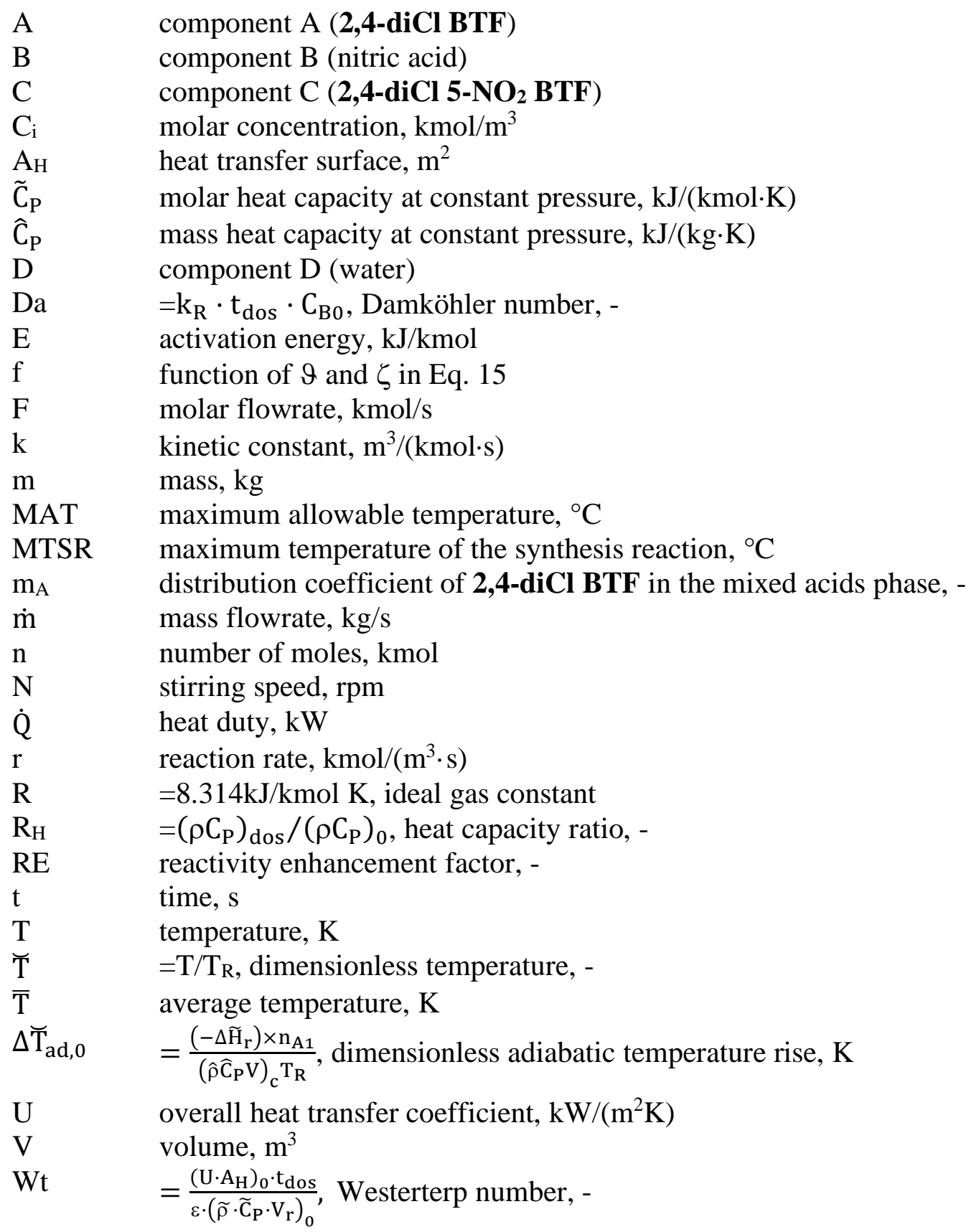

\section{Subscripts and superscripts}

$\begin{array}{ll}\text { act } & \text { activation } \\ \text { ad } & \text { adiabatic } \\ \text { avg } & \text { average } \\ \text { A } & \text { component A }(2,4-d i C l ~ B T F) \\ \text { B } & \text { component B (nitric acid) } \\ \text { C } & \text { component C }\left(2,4-d i C l ~ 5-N O_{2} \text { BTF }\right) \\ \text { C } & \text { continuous phase } \\ \text { cool } & \text { coolant or cooling } \\ \text { d } & \text { dispersed phase }\end{array}$




$\begin{array}{ll}\text { D } & \text { component D (water) } \\ \text { dos } & \text { dosing stream or dosing time } \\ \text { eff } & \text { effective } \\ \text { fed } & \text { fed } \\ \text { IN } & \text { inlet } \\ \text { m } & \text { order of reaction with respect to reactant B, - } \\ \text { max } & \text { maximum } \\ \text { n } & \text { order of reaction with respect to reactant A, - } \\ \text { OUT } & \text { outlet } \\ \text { r } & \text { reaction } \\ \text { R } & \text { reference } \\ \text { ta } & \text { target } \\ 0 & \text { start of the semibatch period } \\ 1 & \text { end of the semibatch period }\end{array}$

Greek symbols

$\gamma \quad=\mathrm{E} /\left(\mathrm{RT}_{\mathrm{R}}\right)$, dimensionless activation energy, -

$\Gamma \quad$ coreactant accumulation at the end of the supply period, -

$\Delta \widetilde{\mathrm{H}} \quad$ reaction enthalpy, $\mathrm{kJ} / \mathrm{kmol}$

$\Delta \widehat{\mathrm{H}} \quad$ reaction enthalpy referred to the mass of reacted coreactant, $\mathrm{kJ} / \mathrm{kg}$

$\Delta \mathrm{T} \quad$ temperature rise or difference, $\mathrm{K}$

$\Delta \breve{\mathrm{T}} \quad$ dimensionless temperature rise, -

$\varepsilon$

$=\mathrm{V}_{\mathrm{dos}} / \mathrm{V}_{\mathrm{r} 0}$, relative volume increase, -

conversion of $\mathrm{B}$, -

$\vartheta \quad=\mathrm{t} / \mathrm{t}_{\mathrm{d} o s}$, dimensionless time, -

$\kappa \quad=\mathrm{k} / \mathrm{k}_{\mathrm{R}}$, dimensionless rate constant, -

$v \quad$ stoichiometric coefficient, -

$\tilde{\rho} \quad$ molar density, $\mathrm{kmol} / \mathrm{m}^{3}$

$\hat{\rho} \quad$ mass density, $\mathrm{kg} / \mathrm{m}^{3}$

$\mathrm{X} \quad \mathrm{X}$ number, -

$\psi \quad$ dimensionless temperature rise, -

$\Psi \quad \Psi$ number, -

$\omega \quad$ mass fraction, - 


\section{$\underline{\text { References }}$}

(1) Douglas, J. M. Conceptual Design of Chemical Processes; McGraw Hill: New York, 1988.

(2) Steinbach, J. Safety Assessment for Chemical Processes; Wiley-VCH: Weinheim, 1999.

(3) Steensma, M.; Westerterp, K. R. Thermally Safe Operation of a Cooled Semibatch Reactor. Slow Liquid-Liquid Reactions. Chem. Eng. Sci. 1988, 43, 2125.

(4) Steensma, M.; Westerterp, K. R. Thermally Safe Operation of a Semibatch Reactor for LiquidLiquid Reactions. Slow Reactions. Ind. Eng. Chem. Res. 1990, 29, 1259.

(5) Steensma, M.; Westerterp, K. R. Thermally Safe Operation of a Semibatch Reactor for LiquidLiquid Reactions. Fast Reactions. Chem. Eng. Technol. 1991, 14, 367.

(6) Maestri, F.; Rota, R. Thermally Safe Operation of Liquid-Liquid Semibatch Reactors. Part I: Single Kinetically Controlled Reactions with Arbitrary Reaction Order. Chem. Eng. Sci. 2005, 60, 3309.

(7) Maestri, F.; Rota, R. Thermally Safe Operation of Liquid-Liquid Semibatch Reactors. Part II: Single Diffusion Controlled Reactions with Arbitrary Reaction Order. Chem. Eng. Sci. 2005, 60, 5590.

(8) Maestri, F.; Rota, R. Safe and Productive Operation of Homogeneous Semibatch Reactors. I: Development of a General Procedure. Ind. Eng. Chem. Res. 2006, 45, 8002.

(9) Maestri, F.; Copelli, S.; Rota, R.; Lunghi, A.; Gigante, L.; Cardillo, P. Simple Procedure for Optimal Scale-up of Fine Chemical Processes. I: Practical Tools. Ind. Eng. Chem. Res. 2009, 48, 1307.

(10) Copelli, S.; Derudi, M.; Sempere, J.; Serra, E.; Lunghi, A.; Pasteurenzi, C.; Rota, R. Emulsion polymerization of vinyl acetate: safe optimization of a hazardous complex process. J. Hazardous Mat. 2011, 192, 8.

(11) Copelli, S.; Derudi, M.; Maestri, F.; Rota, R. Safe operating conditions for semibatch processes involving consecutive reactions with autocatalytic behavior. Chem. Eng. Sci. 2010, 65, 5464. 
(12) Maestri, F.; Rota, R. Kinetic-Free Safe Operation of Fine Chemical Runaway Reactions: a General Criterion. Ind. Eng. Chem. Res. 2016, 55, 925.

(13) Maestri, F.; Rota, R. Simple Monitoring of Semibatch Polymerization Processes: An Integrated Criterion. Ind. Eng. Chem. Res. 2017, 56, 7434.

(14) Maestri, F.; Copelli, S.; Rizzini, M.; Rota, R. Safe and Selective Monitoring of Consecutive Side Reactions Ind. Eng. Chem. Res. 2017, 56, 11075.

(15) Curti, S. Studio sulla Sicurezza di una Reazione di Nitrazione di Interesse Industriale. Master Thesis in Industrial Chemistry, Università degli Studi di Milano, Milano, IT, 1998 (in Italian).

(16) Marhold, A.; Klauke, E. Process for the Preparation of Trifluoromethylphenols. U.S. Patent 4,225,731, 1980.

(17) Maestri, F.; Copelli, S.; Rota, R.; Lunghi, A.; Gigante, L.; Cardillo, P. Simple Procedure for Optimal Scale-up of Fine Chemical Processes. II: Nitration of 4-Chlorobenzotrifluoride. Ind. Eng. Chem. Res. 2009, 48 (3), 1316.

(18) Maestri, F.; Rota, R. Kinetic-Free Safe Optimization of a Semibatch Runaway Reaction: Nitration of 4-Chloro Benzotrifluoride. Ind. Eng. Chem. Res. 2016, 55, 12786.

(19) Cardillo, P. Incidenti in Ambiente Chimico. Guida allo Studio e alla Valutazione delle Reazioni Fuggitive; Stazione Sperimentale per i Combustibili: San Donato Milanese, 1998 (in Italian).

(20) Copelli, S.; Derudi, M.; Cattaneo, C. S.; Nano, G., Raboni, M.; Torretta, V.; Rota, R. Synthesis of 4-Chloro-3-nitrobenzotrifluoride: Industrial Thermal Runaway Simulation due to Cooling System Failure. Process. Saf. Environ. 2014, 92, 659.

(21) Albright, L. F. Nitration. In Kirk Othmer - Encyclopedia of Chemical Technology; Third Ed.; Wiley \& Sons: New York, 1981; Vol. 15, p. 841.

(22) Yaws, C. L. Chemical Properties Handbook; McGraw Hill, 1998.

(23) Zaldivar, J. M. Atti del Convegno: Nitrazioni Sicure in Laboratorio e in Impianto Industriale. Presented at Stazione Sperimentale per i Combustibili, San Donato Milanese, 1996; p. 51 (in Italian). 
(24) Benson, S. W., Thermochemical Kinetics; Second Ed., Wiley \& Sons: New York, 1976.

(25) Stoessel, F. What is your Thermal Risk? Chem. Eng. Prog. 1993, 68.

(26) Zaldivar, J. M.; Molga, E.; Alós, M. A.; Hernández, H.; Westerterp, K. R. Aromatic Nitrations by Mixed Acids. Slow Liquid-Liquid Reaction Regime. Chem. Eng. Process.: Process Intensification 1995, 34, 543.

(27) Zaldivar, J. M.; Molga, E.; Alós, M. A.; Hernández, H.; Westerterp, K. R. Aromatic Nitrations by Mixed Acids. Fast Liquid-Liquid Reaction Regime. Chem. Eng. Process.: Process Intensification 1996, 35, 91.

(28) Westerterp, K. R.; van Swaaij, W. P. M.; Beenackers, A. A. C. M. Chemical Reactor Design and Operation; Wiley, Chichester, 1984.

(29) Morrison, R. T.; Boyd, R. N. Organic Chemistry; Sixth Ed., Prentice Hall of India, New Delhi, 2002.

(30) Smith, M.; March, J. Advanced Organic Chemistry: Reactions, Mechanisms and Structure; Sixth Ed., Wiley, New York, 2007.

(31) Pohorecki, R.; Molga, E. Letter to the Editor: the Westerterp Number (Wt). Chem. Eng. Res. and Des. 2010, 88, 385.

(32) Westerterp, K. R.; Molga, E. J. No More Runaways in Fine Chemical Reactors. Ind. Eng. Chem. Res. 2004, 43, 4585.

(33) Copelli, S.; Torretta, V.; Pasteurenzi, C.; Derudi, M.; Cattaneo, C. S.; Rota, R. On the divergence criterion for runaway detection: Application to a complex controlled system. J. loss Prev. Proc. Ind. 2014, 28, 92.

(34) Valdes, O. J. R.; Casson Moreno, V.; Waldram, S. P.; Véchot, L. N.; Mannan, M. S. Experimental Sensitivity Analysis of the Runaway Severity of Dicumyl Peroxide Decomposition using Adiabatic Calorimetry. Thermochimica Acta 2015, 617, 28.

(35) Maschio, G.; Lister, D. G.; Casson Moreno, V. Use of Screening Analysis Calorimetry in the Study of Peroxides Decomposition. Chemical Engineering Transactions 2012, 19, 347. 
(36) Etchell, J.; Wilday, J. Workbook for Chemical Reactor Relief System Sizing. CRR 1998/136.

HSE Health and Safety Executive, Crown Copyright, 1998. 
$\underline{\text { Tables }}$

Amount:

Species:

Initial load:

$108 g$

$\mathrm{HNO}_{3}$

$\frac{1100 \mathrm{~g}}{1208 \mathrm{~g}\left(\equiv 676 \mathrm{~cm}^{3} \text { with } \hat{\rho}_{\mathrm{c}}=1787 \mathrm{~kg} / \mathrm{m}^{3}\right)}$

$\mathrm{H}_{2} \mathrm{SO}_{4}$

Dosed coreactant:

$335 \mathrm{~g}\left(\equiv 233 \mathrm{~cm}^{3}\right.$ with $\left.\hat{\rho}_{\mathrm{d}}=1440 \mathrm{~kg} / \mathrm{m}^{3}\right)$

2,4-di Cl BTF

Initial temperature:

$55^{\circ} \mathrm{C}$

Maximum temperature: $\quad 65^{\circ} \mathrm{C}$

Table 1. Chemical recipe at the laboratory scale. 


\section{RC1 reactor}

Volume:

Initial heat transfer surface:

Stirring speed:

Initial UA:

Final UA:

Average UA:

\section{Industrial SBR}

a) Dimensional parameters

Volume:

Initial heat transfer surface:

Stirring speed:

Initial UA:

Final UA:

Average UA:

b) Dimensionless parameters

$\begin{array}{lll}\text { Activation energy } & \gamma & 35.16 \\ \text { Adiabatic temperature rise } & \Delta \widetilde{\mathrm{T}}_{\mathrm{ad}, 0} & 0.443 \\ \text { Relative volume increase } & \varepsilon & 0.344 \\ \text { Heat capacity ratio } & \mathrm{R}_{\mathrm{H}} & 0.642 \\ \text { Westerterp number } & \mathrm{Wt} & \left.40 \text { (with } \mathrm{E}_{\mathrm{x}} \approx 1\right)\end{array}$

$3.605 \times 10^{-2} \mathrm{~m}^{2}$
$9 m^{3}$

$45 m^{2}$

300rpm

$12 \mathrm{~kW} / \mathrm{K}$

$16.1 \mathrm{~kW} / \mathrm{K}$

$14.1 \mathrm{~kW} / \mathrm{K}$
$\mathrm{V}_{\mathrm{c}}=676 \mathrm{~cm}^{3}$

$V_{d}=233 \mathrm{~cm}^{3}$

300rpm

$5.56 \mathrm{~W} / \mathrm{K}$

$7.47 \mathrm{~W} / \mathrm{K}$

$6.52 \mathrm{~W} / \mathrm{K}$
$\mathrm{V}_{\mathrm{c}}=4.688 \mathrm{~m}^{3}$

$\mathrm{V}_{\mathrm{d}}=1.613 \mathrm{~m}^{3}$ 


\section{Captions to the figures}

Figure 1. DSC thermoanalytical curve (experimental data from ${ }^{13}$ ) for: (A) 2,4-diCI BTF; stainless steel crucible; heating rate: $10^{\circ} \mathrm{C} /$ minute. (B) 2,4-diCl 5-NO $\mathbf{N O}_{2} \mathbf{B T F}$; stainless steel crucible coated with gold; heating rate: $10^{\circ} \mathrm{C} /$ minute.

Figure 2. DSC thermoanalytical curve (experimental data from ${ }^{13}$ ) for the final nitration mixture; stainless steel crucible coated with gold; heating rate: (A) $10^{\circ} \mathrm{C} /$ minute; (B) $5^{\circ} \mathrm{C} /$ minute; (C) $1^{\circ} \mathrm{C} /$ minute.

Figure 3. Isothermal RC1 runs (experimental data from ${ }^{13}$ ). Mixed acids initial composition: $\sim 9 \%$ w/w of nitric acid. (A) $300 \mathrm{rpm}$ and $60^{\circ} \mathrm{C}$ (I), $55^{\circ} \mathrm{C} \mathrm{(II).} \mathrm{(B)} 60^{\circ} \mathrm{C}$ and 300rpm (I), 150rpm (II), 130rpm (III), 100rpm (IV).

Figure 4. Isothermal RC1 runs at $60^{\circ} \mathrm{C}$. Mixed acids initial composition: $\sim 9 \% \mathrm{w} / \mathrm{w}$ of nitric acid. Coreactant accumulation at the end of the dosing period vs. stirring speed.

Figure 5. Isoperibolic RC1 runs with $\mathrm{T}_{\text {cool }}=\mathrm{T}_{0}=55^{\circ} \mathrm{C}$. Mixed acids initial composition: $\sim 9 \% \mathrm{w} / \mathrm{w}$ of nitric acid. 2,4-diCl BTF dosing time: 30' (A); 60' (B); 90’ (C). Reaction temperature vs. dimensionless time (A); $\Psi$ number vs. dimensionless time (B).

Figure 6. Industrial SBR operated with $\mathrm{T}_{\text {cool }}=\mathrm{T}_{0}=55^{\circ} \mathrm{C}$. Mixed acids initial composition: $\sim 9 \% \mathrm{w} / \mathrm{w}$ of nitric acid. 2,4-diCl BTF dosing time: 4 hours. Reaction temperature vs. time (A); $\Psi$ number vs. time (B); X number vs. time (C); MTSR $_{a d}$ vs. time (D).

Figure 7. Industrial SBR operated with $\mathrm{T}_{\text {cool }}=\mathrm{T}_{0}=55^{\circ} \mathrm{C}$. Mixed acids initial composition: $\sim 9 \% \mathrm{w} / \mathrm{w}$ of nitric acid. 2,4-diCI BTF dosing time: 4 hours. Heat transfer efficiency drop occurring in the last $10 \%$ of the supply period. Reaction temperature vs. time (A); $\Psi$ number vs. time (B); X number vs. time (C); MTSRad vs. time (D).

Figure 8. Industrial SBR operated with $\mathrm{T}_{\text {cool }}=\mathrm{T}_{0}=55^{\circ} \mathrm{C}$. Mixed acids initial composition: $\sim 9 \% \mathrm{w} / \mathrm{w}$ of nitric acid. Coreactant dosing time: 4 hours. $\Psi$ number time behavior for the 4-Cl BTF and for the 2,4-diCl BTF nitration.

Figure 9. Industrial SBR operated with $\mathrm{T}_{\text {cool }}=\mathrm{T}_{0}=55^{\circ} \mathrm{C}$. Mixed acids initial composition: $\sim 9 \% \mathrm{w} / \mathrm{w}$ of nitric acid. Coreactant dosing time: 4 hours. X number time behavior for the 4-Cl BTF and for the 2,4-diCI BTF nitration.

Figure 10. Industrial SBR operated with $\mathrm{T}_{\text {cool }}=\mathrm{T}_{0}=55^{\circ} \mathrm{C}$. Mixed acids initial composition: $\sim 9 \% \mathrm{w} / \mathrm{w}$ of nitric acid. Coreactant dosing time: 4 hours. MTSR ${ }_{a d}$ time behavior for the 4-Cl BTF and for the 2,4-diCl BTF nitration. 


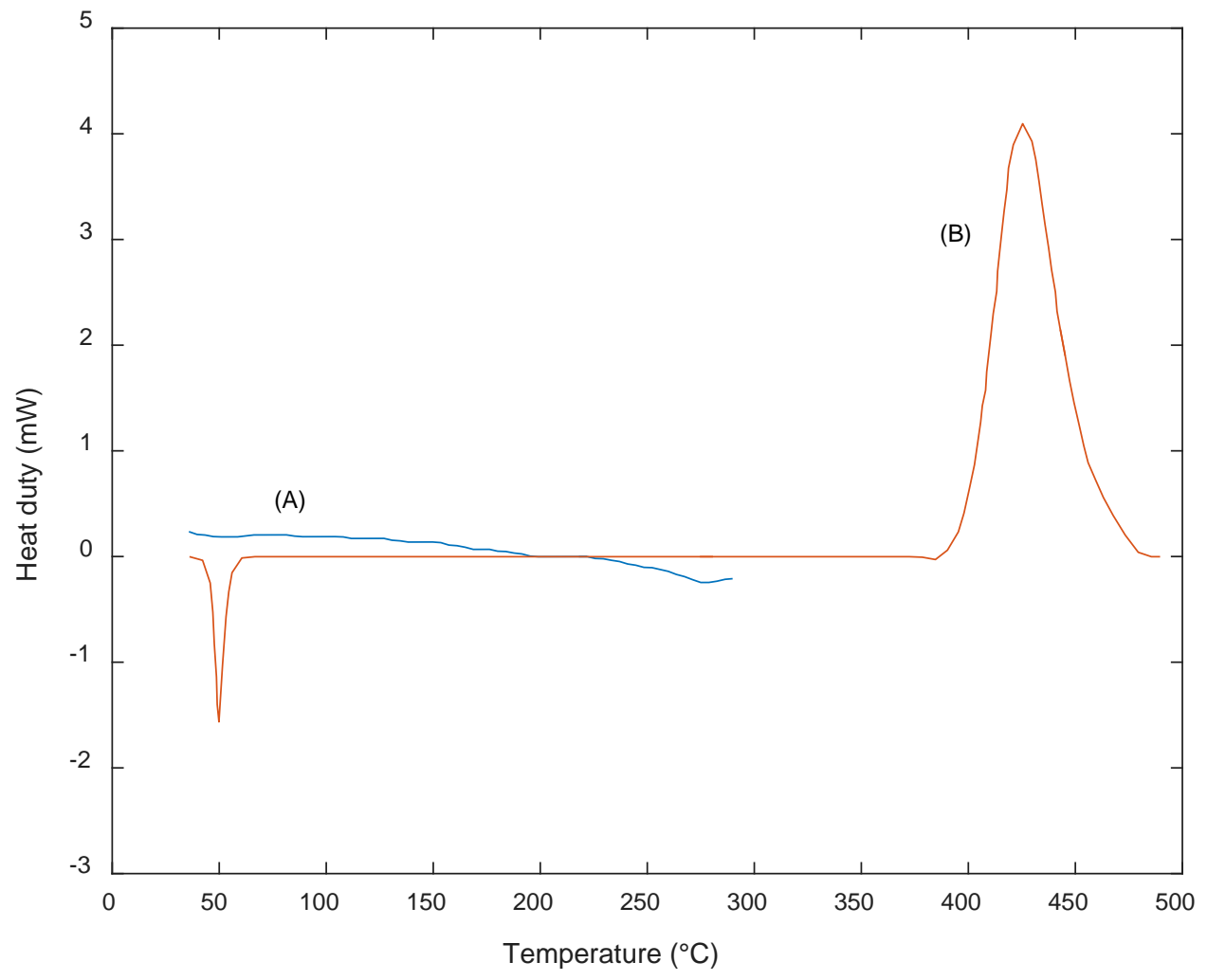

Fig.1 


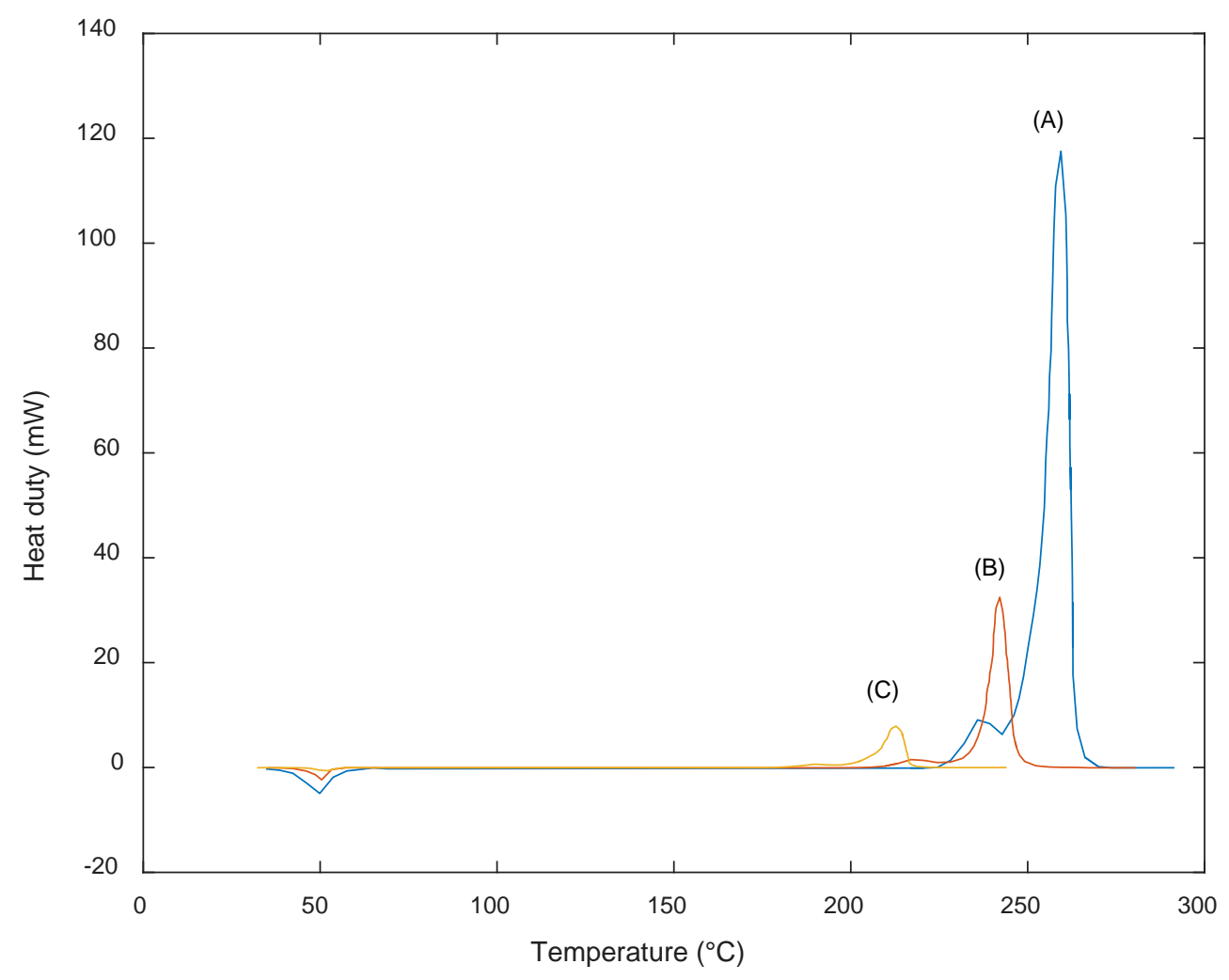

Fig. 2 

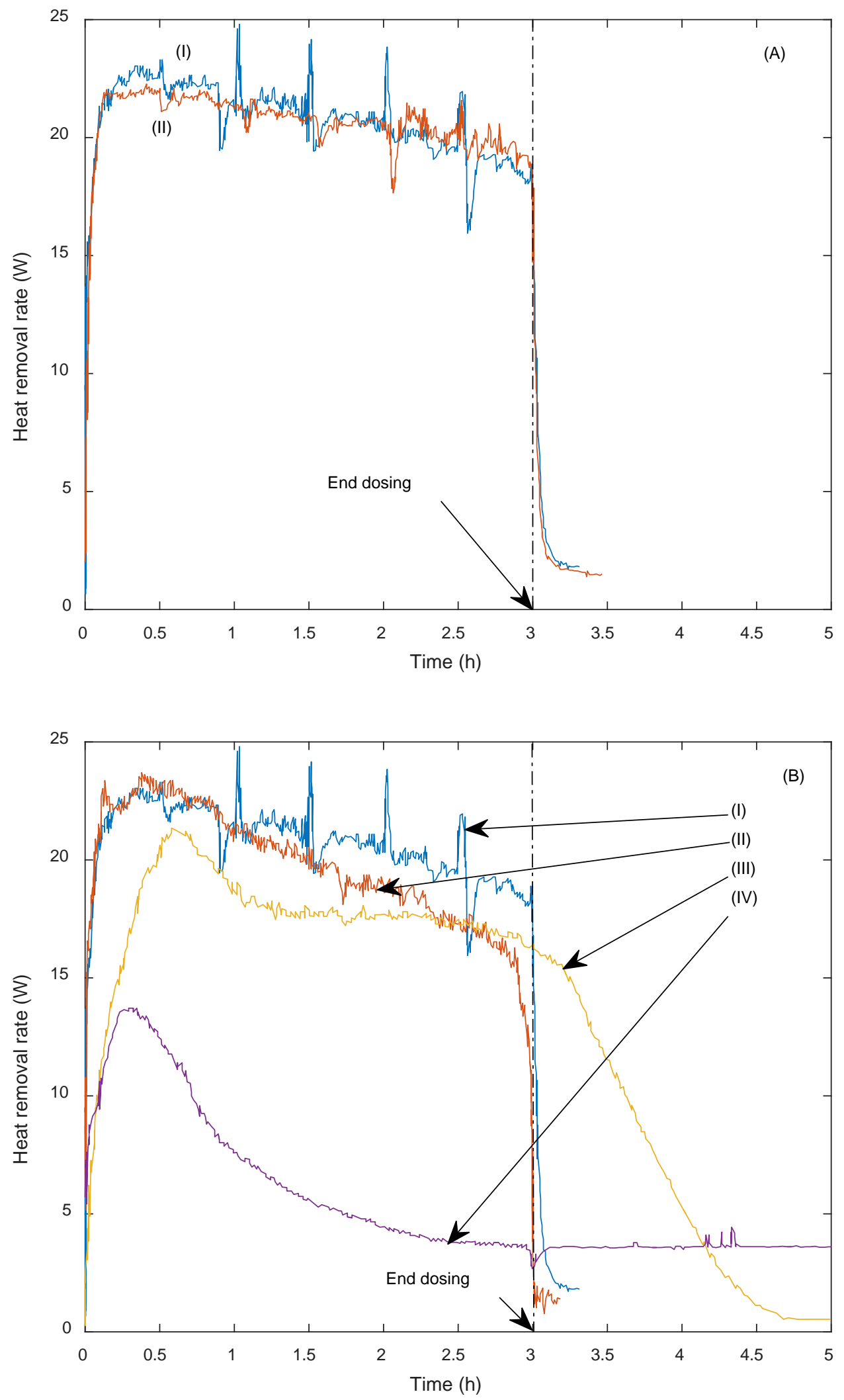

Fig. 3 


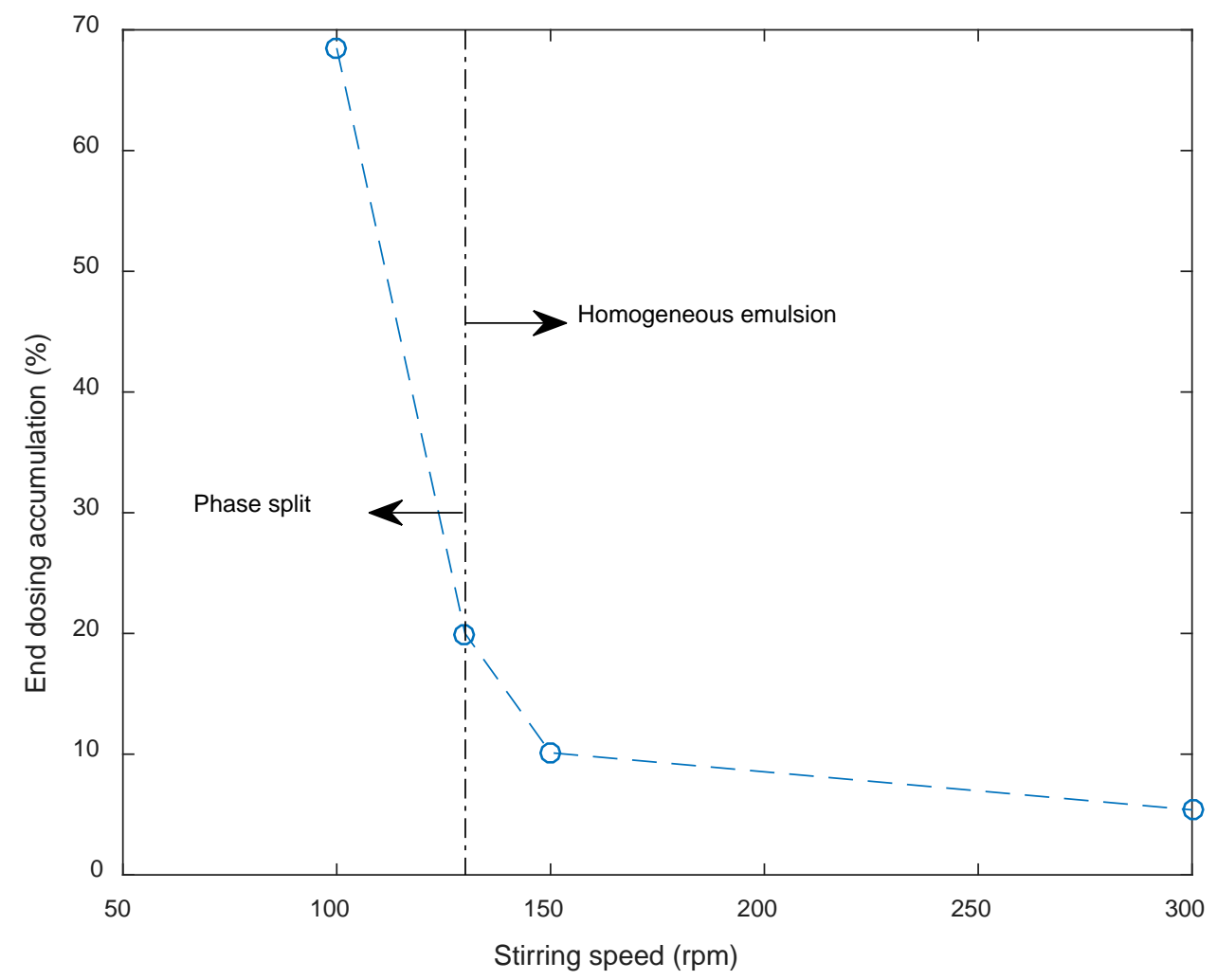

Fig. 4 

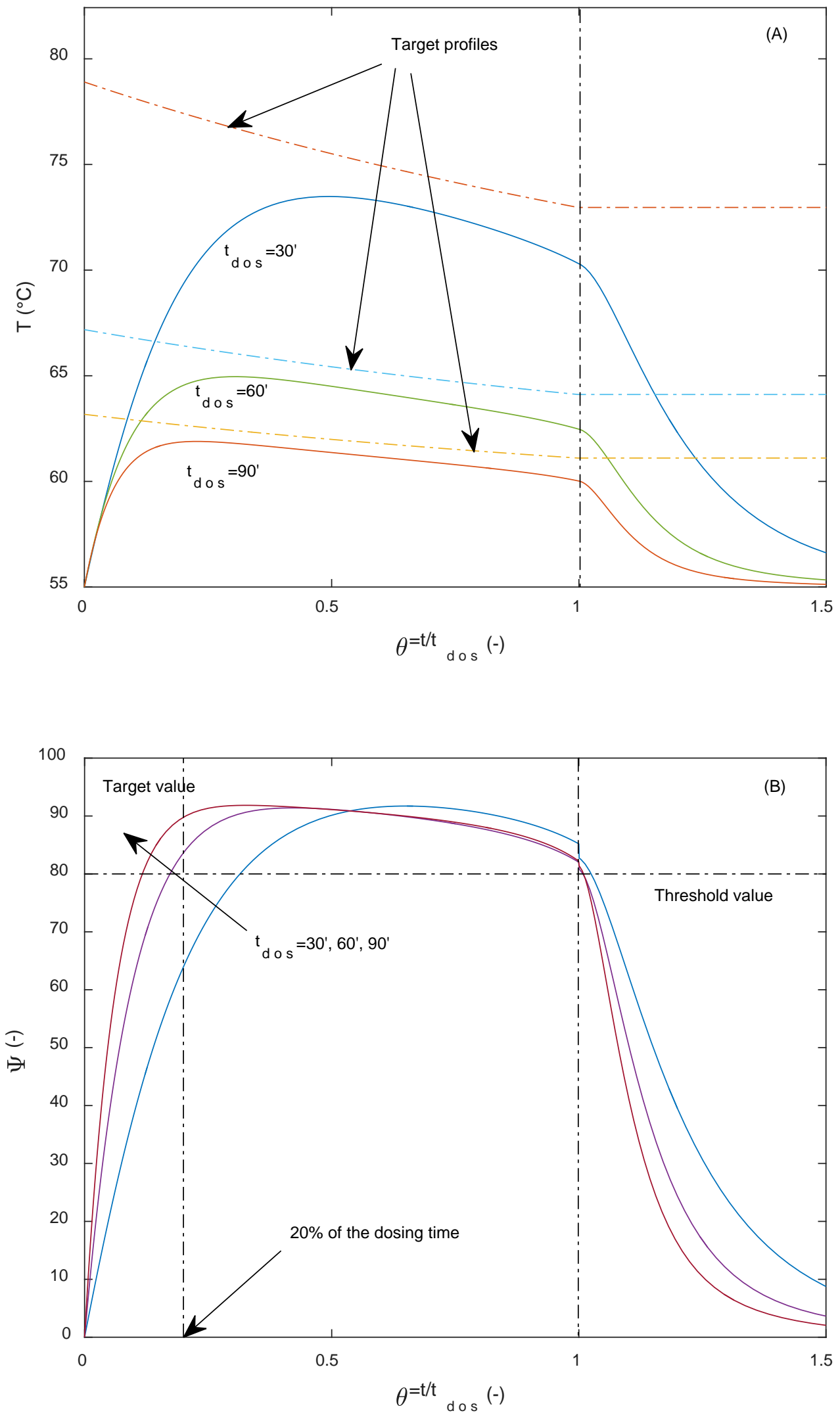

Fig. 5 

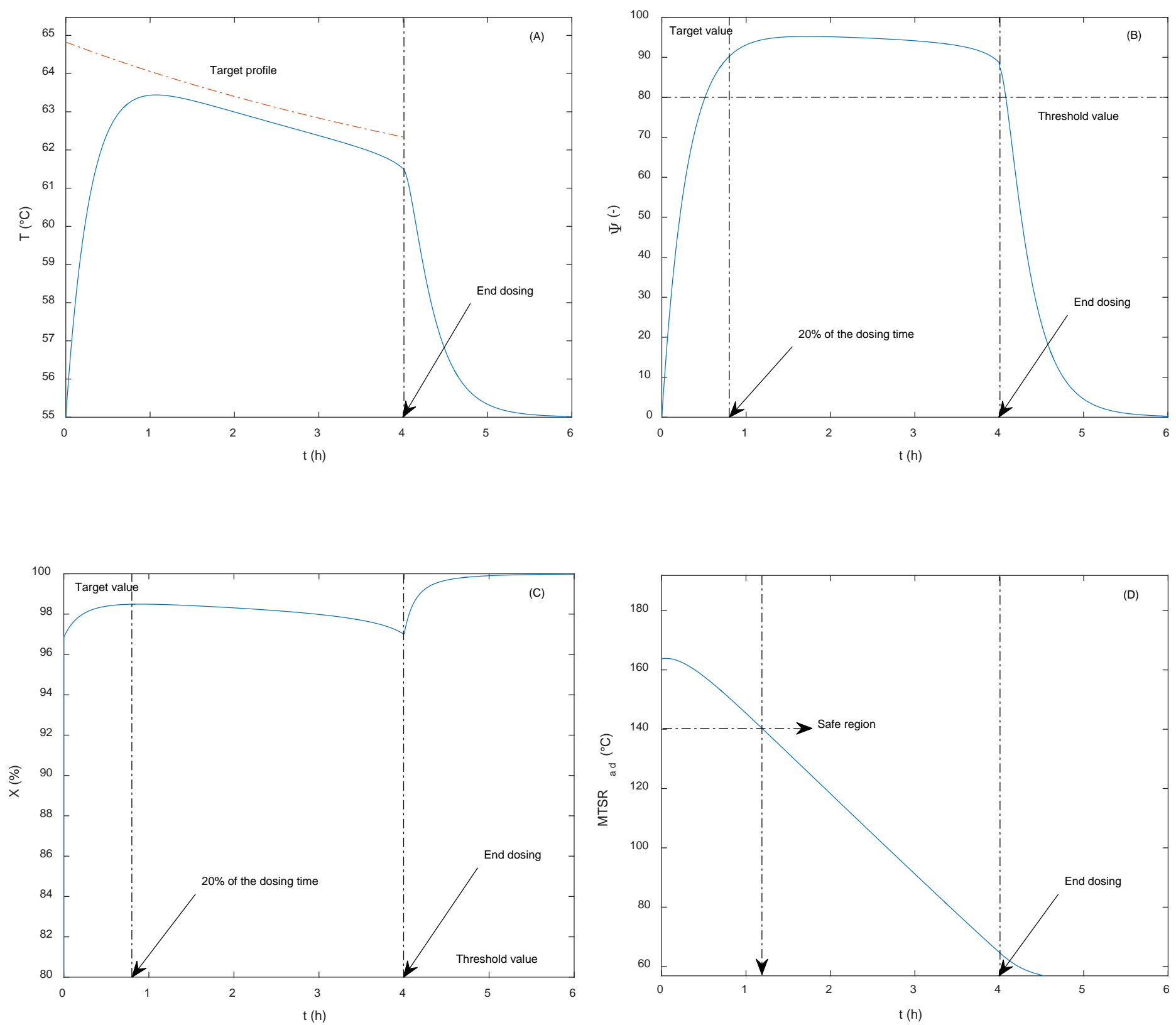

Fig. 6 

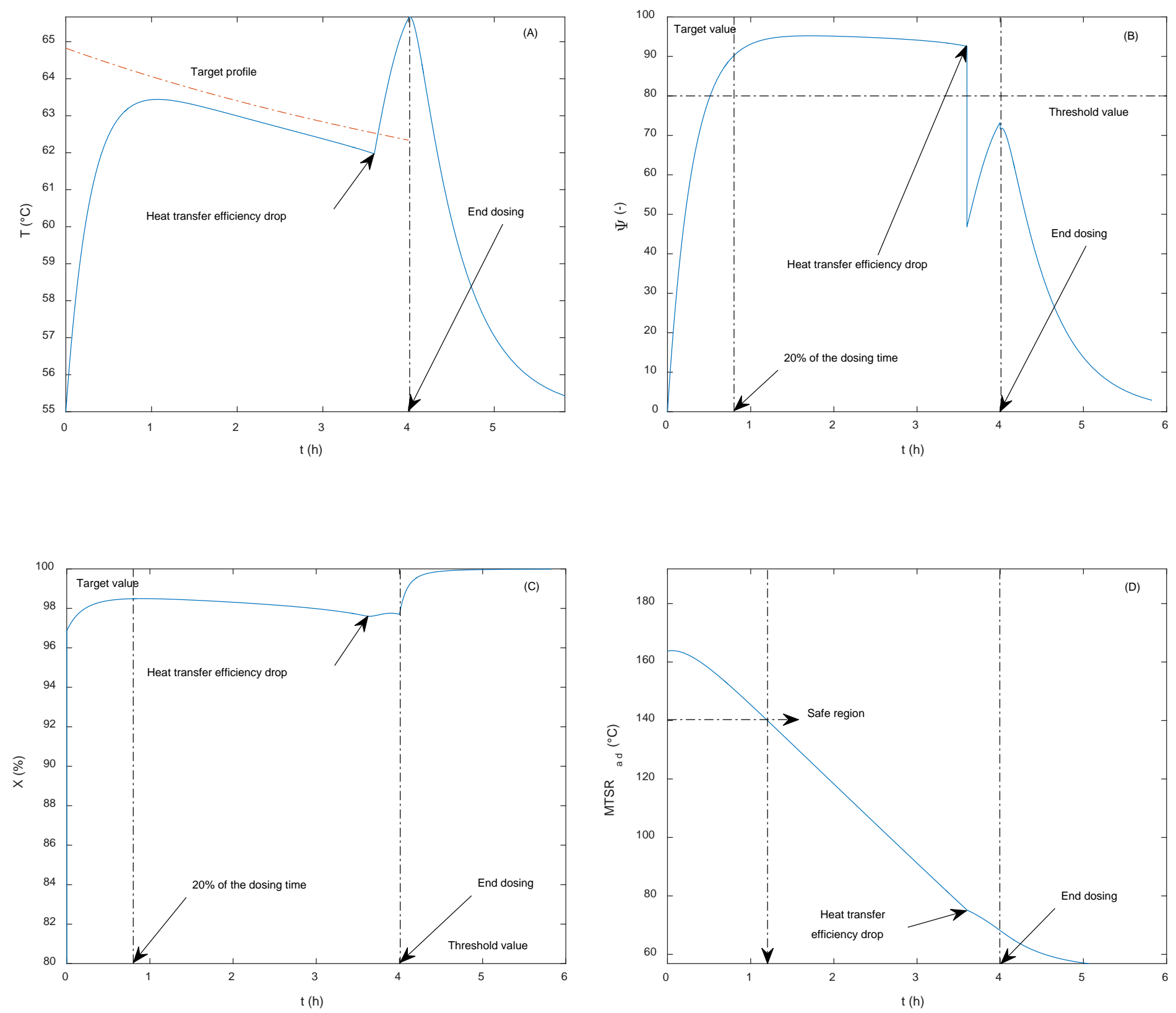

Fig. 7 


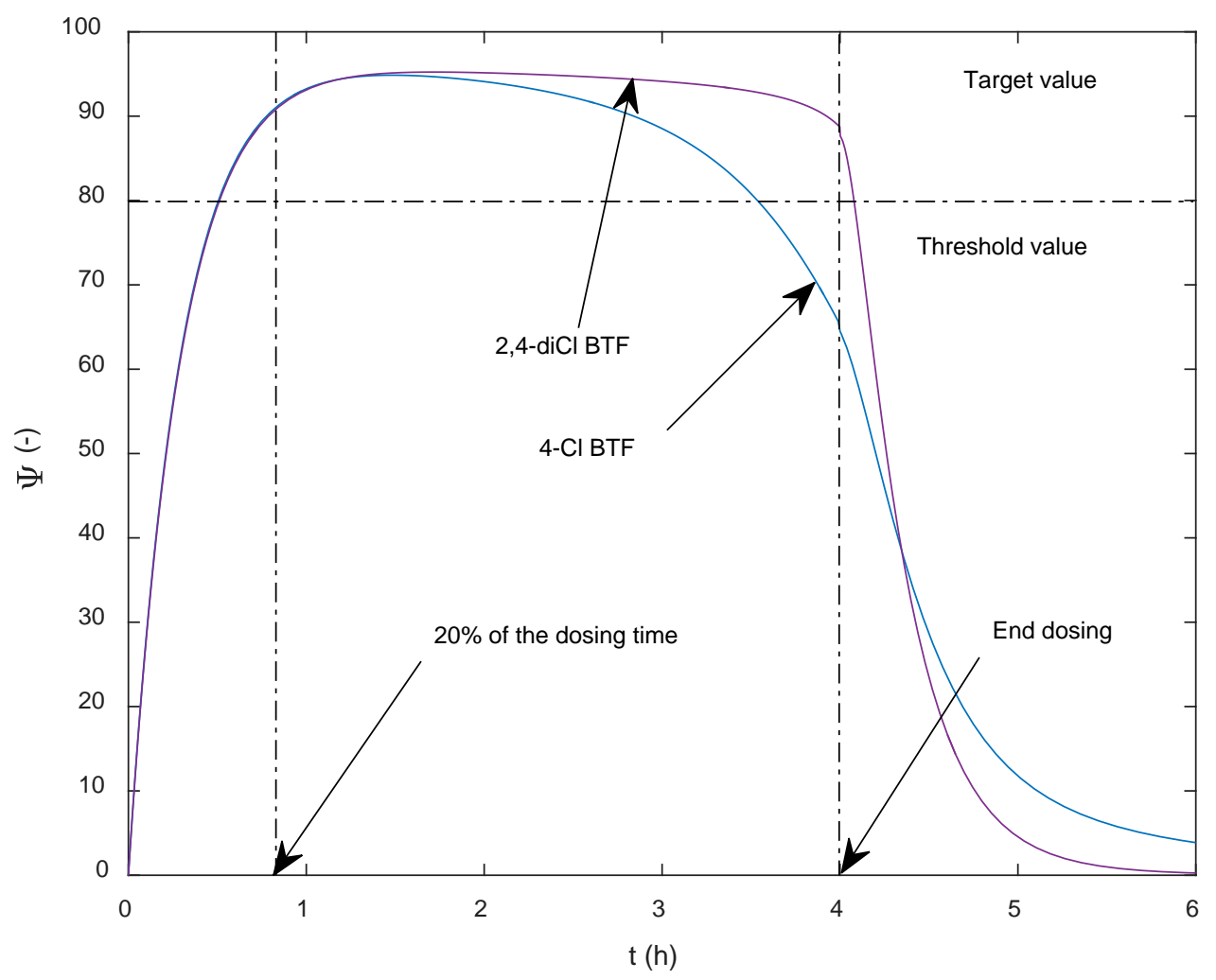

Fig. 8

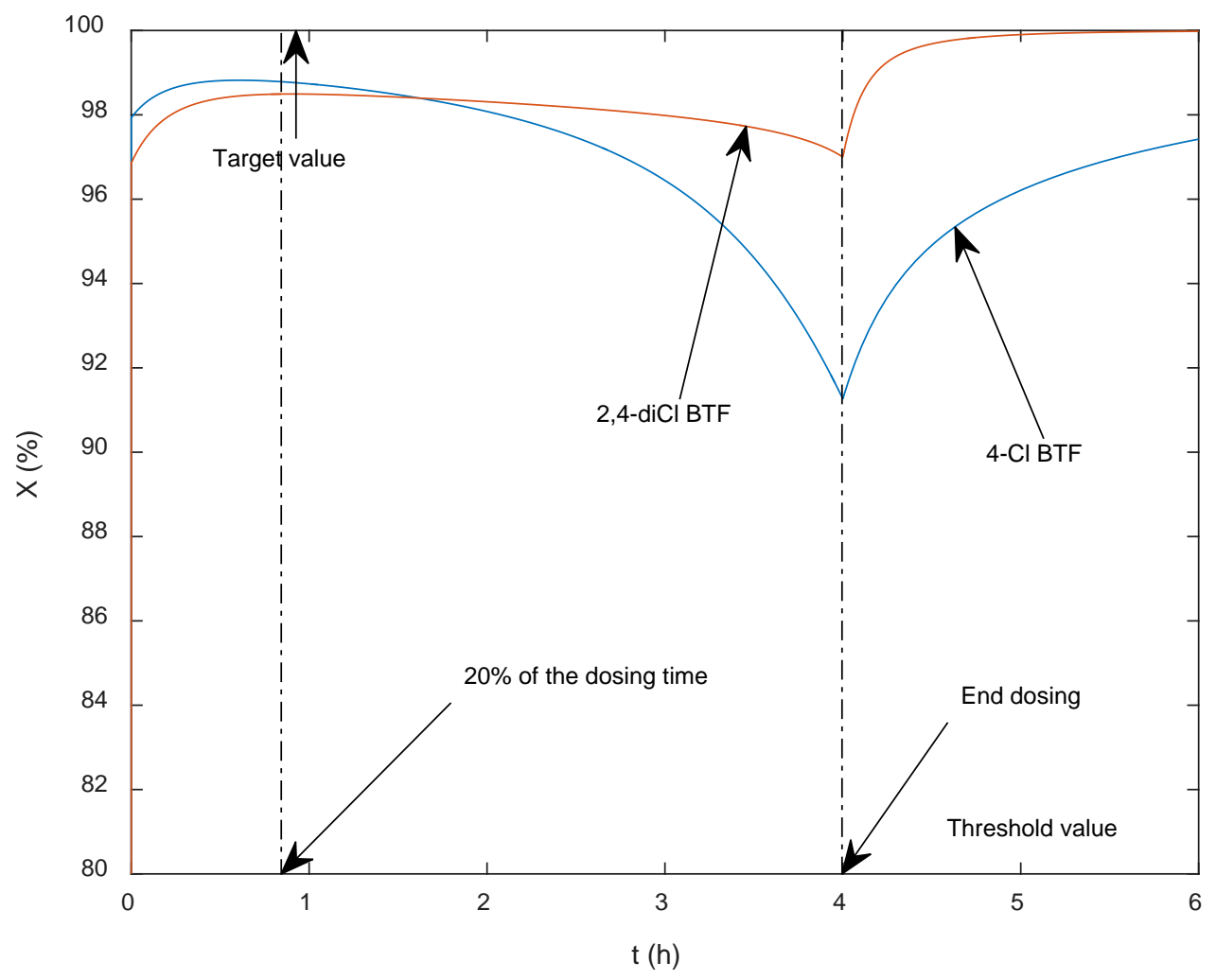

Fig. 9 


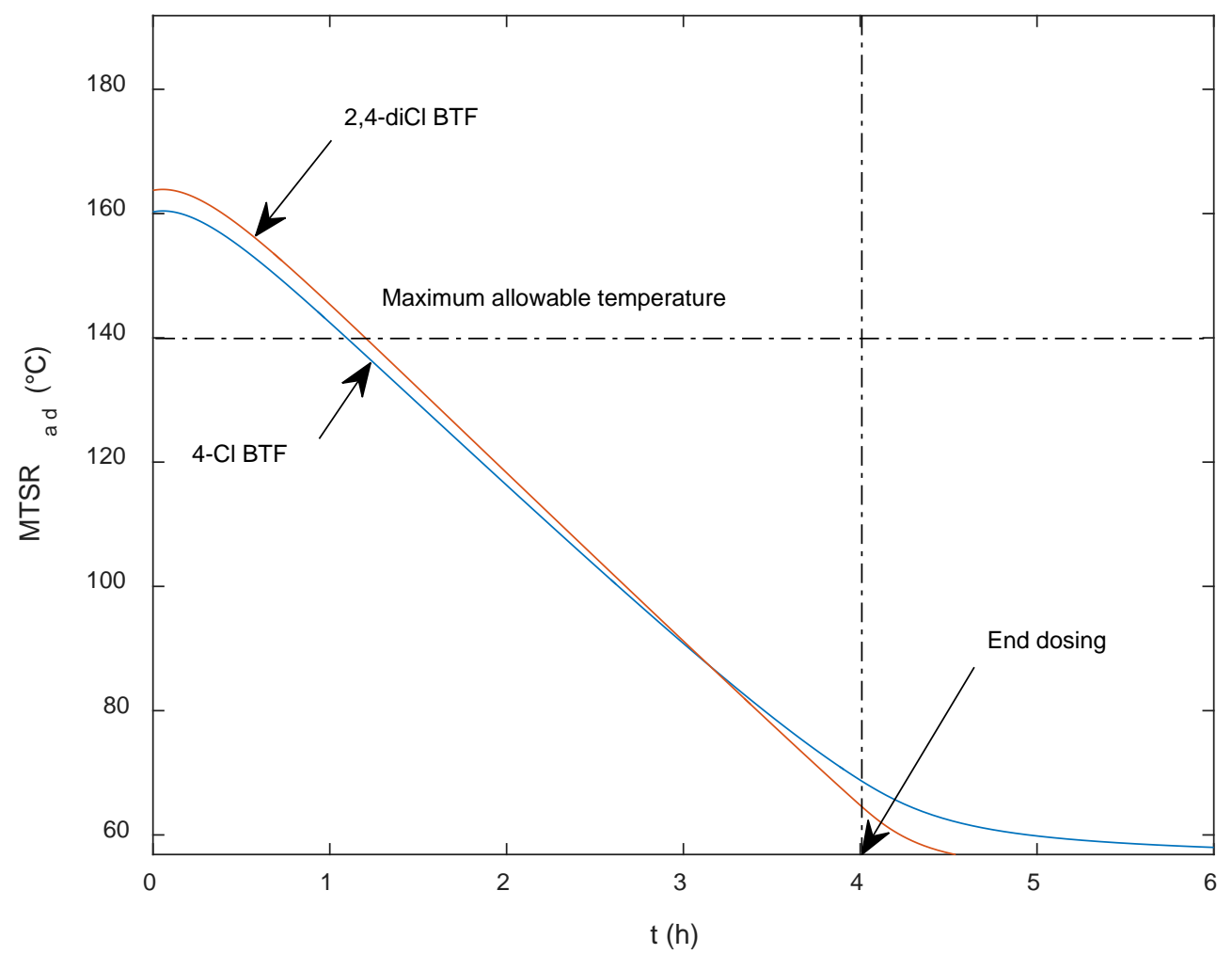

Fig. 10 


\section{For Table of Contents Only}

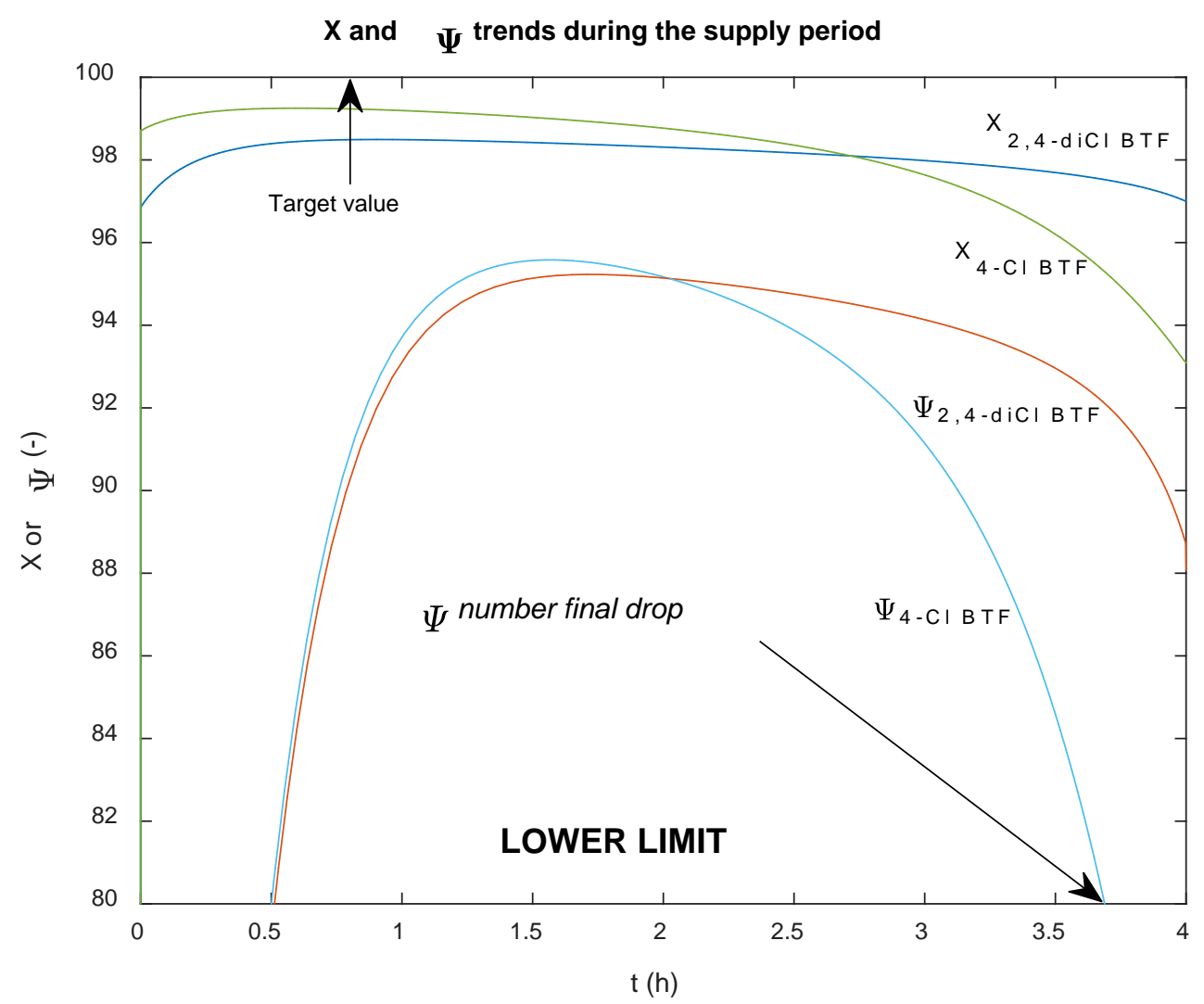

